REVISTA LEGEM

ISSN Online 2346-2787

\title{
Libertad por vencimiento de término y el derecho al plazo razonable de la medida de aseguramiento en la jurisprudencia
}

\author{
Freedom by term expiration and the right \\ to the reasonable term of the insurance measure \\ in the jurisprudence
}

\author{
(iD) \\ Alejandro Ibáñez Macías* \\ Universidad Libre, Colombia \\ a.ibanezmacias@gmail.com
}

https://doi.org/10.15648/legem.1.2020.2661

Recibido: 07 de febrero de 2020/ Aceptado: 11 de julio de 2020

\begin{abstract}
Resumen
El derecho al vencimiento de términos es considerado como aquella facultad con la que cuenta el procesado en el evento que el Estado no cumple con los términos procesales para resolver situación jurídica; cuando se desbordan estos términos de manera injustificada este es llamado a recobrar su libertad, no obstante, este plazo razonable puede extenderse a las señaladas por la ley, pero estas mismas deben ser acreditadas, no basta con un examen a la ligera, toda vez que al tratarse de un derecho de tal relevancia, este mismo debe ser analizado cuidadosamente, siempre inclinándose toda duda a favor del privado de la libertad, en caso de proceder circunstancias que da lugar a la extensión de dicha medida, estas deben ser analizadas de manera minuciosa, y así mismo debe pasar a justificarse y aprobar un examen de argumentación que permita concluir el porqué no se reconocerá el derecho a la libertad.
\end{abstract}

Palabras clave: vencimiento de términos, plazo razonable, medida de aseguramiento, maniobras dilatorias, derecho a la defensa y principio de inocencia.

\section{ABSTRACT}

The right to expiration of terms is considered as that power that the defendant has in the event that the State does not comply with the procedural terms to resolve the legal situation; when these terms are unreasonably overflowed, he is called to regain his freedom, however, this reasonable period may be extended to those set by law, but these must be accredited, a brief examination is not enough, since As it is a right of such relevance, it must be carefully analyzed, always tilting any doubt in favor of the person deprived of liberty, in the event that circumstances that give rise to the extension of said measure proceed, these must be carefully analyzed, and likewise must be justify and pass an argument test that allows concluding why the right to freedom will not be recognized.

Keywords: expiration of terms, reasonable term, assurance measure, delaying maneuvers, right to defense and principle of innocence

Como citar: Ibáñez Macías, A. (2020). Libertad por vencimiento de término y el derecho al plazo razonable de la medida de aseguramiento en la jurisprudencia. Revista LEGEM, 6(1), 1-16. https://doi.org/10.15648/legem.1.2020.2661

*Abogado, Magister en Derecho Penal. Defensor Publico ante los jueces penales municipales. 


\section{Introducción}

La responsabilidad penal es una consecuencia jurídica que por regla general debe ser comprobada con juicio, estadio donde se debe materializar todas las garantías del involucrado dentro del proceso, encontramos dentro de esa pluralidad de garantías el principio de inocencia, uno de los grandes avances dentro de la humanización del proceso penal en la historia, que en palabras sencillas lo señalaremos como, toda persona se presume inocente hasta que dentro de un proceso se demuestre su culpabilidad, hasta que en ese proceso no culmine con una respectiva providencia que concluya que la persona es responsable de la conducta que se le reprocha, este se presume inocente; ahora bien, ese proceso por el cual se va desvirtuar ese principio de inocencia tiene sus pautas y garantías, por lo cual, no se puede tomar como un proceso que puede resolverse de manera inmediata, puesto que el derecho fundamental a la libertad no puede ser llamado a un derecho que puede ser degradado a la ligera, la responsabilidad penal debe probarse mas allá de duda razonable. Ahora bien, mientras se adelanta dicho proceso, la libertad puede ser afectada, atendiendo la institución de la medida de aseguramiento, reconocida como una medida de carácter temporal que permite afectar algunos derechos atendiendo unos fines constitucionales dentro de un plano de la proporcionalidad, que en los casos que lo requiera en atención puede ser privativa de la libertad; sin pasar por alto, como se menciono, estas medidas son de carácter temporal, que tiene su duración atendiendo criterios de plazos razonables, permite ser de carácter legal y en consecuencia exigibles, sin embargo, encontramos situaciones en el que estos plazos razonables no pueden ser cumplidos y en consecuencia, dicha medida pasa a ser ilegal e inexigible, y en consecuencia, la persona que no se le desvirtuó ese principio de inocencia dentro de los términos razonable, recobrar su libertad, sin que esto signifique que el juicio de reproche por la conducta punible por la que investigue o acuse cese, lo que refiere a esa consecuencia es que esté involucrado gozara de libertad hasta que el debate de responsabilidad permita al juez tomar una respectiva decisión.

En el presente artículo de reflexión permitirá señalar cuáles son los criterios y/o presupuesto que deben ser tenidos en cuenta para que se reconozca el derecho a la libertad de vencimiento de términos por violación a la garantía del plazo razonable dentro de un proceso penal con tendencias acusatorias; lo anterior con la finalidad estudiar que si bien el derecho a la libertad no es absoluto y este puede ser restringido por una medida de aseguramiento excepcionalmente, como es la privativa de la libertad, esta no excluida de los parámetros dentro de los términos procesales razonables que son reconocidos por nuestra jurisprudencia nacional e internacional.

\section{La medida de aseguramiento y el principio de inocencia}

La medida de aseguramiento de esta llamada a prosperar de manera injustificada, nuestro legislador ha materializado dicha garantía atendiendo lo señalado en el articulado 308 de nuestra norma procesal penal, que impone al juez de control de garantías que para proceder debe pasar por el primer requisito de que atendiendo los elementos de conocimiento suministrados por la fiscalía se puede demostrar una inferencia razonable en la que el imputado pueda ser responsable del delito, posterior a este estadio, procederá a evaluar, con elementos de conocimiento suministrados en verificar y la corrobra que dicha medida, se cumpla los requisitos que el articulo antes mencionado señala tales como (i) que la medida de aseguramiento se muestre como necesaria para evitar que el imputado obstruya el debido ejercicio de la justicia; (ii) que el imputado constituye un peligro para la seguridad de la sociedad o de la víctima; o (iii) que resulte probable que el imputado no comparecerá al proceso o que no cumplirá la sentencia. 
Una vez satisfechos los anteriores requisitos procederá atendiendo un juicio de proporcionalidad, a verificar la medida a imponer en caso de ser (i) idónea, (ii) necesaria, y (iii) proporcional en estricto sentido; lo anterior sin desconocer en ningún momento su principio de inocencia, puesto que esta diligencia lo que se debate es una inferencia razonable, no una convicción mas allá de duda razonable; sin embargo, dicha situación permite que esta persona se le prive de la libertad ya sea en su residencia o en centro carcelario.

Sentadas las anteriores anotaciones, partiremos de la situación que al imputado se le impuso medida de aseguramiento privativa de la libertad, y en consecuencia se le ha afectado su derecho a la libertad por una medida de aseguramiento, sin pasar por alto la naturaleza de la misma, como señalo la Corte Suprema de Justicia (2017) por su propia naturaleza, la detención preventiva, tiene, entonces, una duración precaria o temporal porque su finalidad no es sancionatoria, no está dirigida a resocializar, a prevenir el delito ni a ejemplarizar, sino que su finalidad es puramente procesal y tiende a asegurar el resultado exitoso del proceso penal (Pág. 13), por lo anterior, esta al ser temporada y no cumplir con unos fines de la pena, está sometida a unos plazos que debe cumplir, en caso de no cumplirse, el procesado será libre, sin embargo, la pregunta que procede a lo anterior seria en señalar, si esta persona recobra su libertad porque este es consecuencia de un beneficio o un derecho, por lo anterior, procederemos a estudiar que ha mencionado nuestra jurisprudencia en el tema de interés.

\section{Antecedentes jurisprudenciales. Libertad por vencimiento de términos, beneficio o derecho}

Iniciando nuestro tema de estudio, procediéremos sin vacilar a señalar que la honorable Corte Suprema de Justicia (2010) fue contundente al señalar que el procesado, en cuyo favor pende la presunción de inocencia, no tiene por qué sufrir la prolongación indeterminada de la privación de la libertad por la ineptitud, negligencia o ineficacia de quienes tienen la misión de administrar justicia. Por eso, la ley ha elevado a la categoría de derecho la libertad provisional, y no a simple beneficio (Pag. 9); lo que permitió determinar en primera instancia que este es un derecho; sin pasar por alto, siendo preciso anotar que esta providencia fue en vigencia de la ley 600 de 2000; una vez entrada en vigencia la ley 906 de 2004 que introdujo un proceso penal con tendencias acusatorias, que dentro de sus múltiples objetivos tiene consigo el acelerar las actuaciones judiciales en materia procesal penal, tanto fue su naturaleza y reconocimiento que dentro del artículo 317 de nuestra norma procesal con tendencias acusatorias, consagro lo relacionado a esta situación de vencimiento de terminos, que a pesar de varias reformas, el enunciado sigue siendo el mismo; sin embargo atendiendo una lectura crítica del mismo, este no señala que si este es un beneficio o es un derecho.

Tiempo después, se dio a conocer la expedición de dos normas, que son 1121 de 2006, y la ley 1098 de 2008, este tipo de normas, señala el doctor Carlos Andrés Gómez que abrió nuevamente el debate, respecto que si este es un beneficio o es un derecho; puesto las normas antes citadas, consagraban un articulo bastante llamativo, al señalar que estas conductas se le excluirían todo tipo de beneficio; partiendo de un estudio sistemático, la Corte Suprema de Justicia (2012) señalo que la libertad por vencimiento de términos era un beneficio, en los casos de las normas antes citadas, no procedería, dentro de los fundamentos de la providencia, señala que existe un prohibición legal, en relación a la potestad con la que cuenta el aparato legislativo en la configuración de creación de preceptos en atención a la política criminal; y siendo más contundente señalo la Honorable Corporación, que la ley 1098 de 2008 de que este no puede denominarse como una prohibición legal, este debe ser categorizado como una prohibición supra-legal asi como lo ha determinado la jurisprudencia, en virtud del interés superior del menor, está en una interpretación sistemática con nuestra constitución política y los tratado internaciones ratificados por Colombia. 
Pasaron los años, hasta que esta interpretación volvió ser objeto de estudio por parte de nuestra Corte Suprema de Justicia (2016), y esta señalo que no puede comprender la exclusión del derecho a ser juzgado en un plazo razonable o ser puesto en libertad, por las razones que ya se expresaron y porque este es un derecho y no un beneficio discusión que de ninguna manera es "bizantina" (Pág. 20), y que esta solo puede ser limitada en los estados de expresión; puesto como lo señalo la Corte Interamericana de Derechos Humanos (1997) señalo:

En el principio de presunción de inocencia subyace el propósito de las garantías judiciales. Con él se afirma la idea de que una persona es inocente hasta que su culpabilidad sea demostrada. El Estado tiene la obligación de no restringir la libertad del detenido más allá de los límites estrictamente necesarios. En caso contrario, se está cometiendo una injusticia, pues ello es tanto como anticipar la pena a la sentencia, lo que es contrario a principios del derecho universalmente reconocidos.

Por lo anterior en sintesis la Corte Suprema de Justicia (2016), señalo que todas las personas privada de la libertad de manera preventiva con independencia al delito por el cual se les vincula en el proceso, y así como el sujeto pasivo del mismo, este tiene un derecho a ser juzgado dentro de un plazo razonable y si esta garantía no se le cumple, esa medida de aseguramiento no puede perpetuarse, en consecuencia tiene el derecho ante el incumpliendo del mismo, a su libertad.

Dando respuesta que la libertad por vencimiento de términos es un derecho; procederemos dar a estudio, que quiere decir eso de plazo razonable, anotando de antemano, que si bien en Colombia el plazo razonable se encuentra cuantificado en nuestra normas procesales vigentes, no puede ser pasado por alto para realizar las respectivas reflexiones, puesto uno de los detalles que mas observa el profesional del derecho, es que los termino no son iguales para todos los casos, cada uno tiene sus términos establecidos, y estos términos fueron adecuando los criterios del plazo razonable, por lo anterior, recalcamos la importancia de entender esta garantía.

\section{Plazo razonable}

Sea lo primero indicar para este concepto nos permitiremos a señalar que este implica dos precisiones, esta (i) la duración del proceso mientras se resuelve la situación jurídica del procesado; y (ii) la permanencia de una persona en detención preventiva mientras se toma dicha decisión; para entender estas implicaciones nos remitiremos al concepto de plazo razonable el cual fue reconocido en la jurisprudencia internacional en los pronunciamientos de la Corte Interamericana de los Derechos Humanos (1997), que si bien no la determina de manera cuantificada como se menciono anteriormente, toda vez, que esta misma señala que esta debe ser valorada atendiendo diversas circunstancias, estas permiten que pueda prolongarse la actividad de la acción jurisdiccional; estas circunstancias y/o criterios que permite justificar la prolongación de la actuación judicial, fueron inicialmente a) la complejidad del asunto; b) la actividad procesal del interesado; c) la conducta de las autoridades judiciales; agregando en providencia de la Corte (2017), la d) situación jurídica de la persona involucrada en el proceso; y la aportada por la Corte Europea y reconocida por la Corte Interamericana de Derecho Humanas la llamada e) análisis global del procedimiento; los cuales la misma jurisprudencia de la Corte Interamericana lo ha desarrollado de la siguiente manera: 


\section{Complejidad del asunto}

Frente a este presupuesto la Corte Interamericana de Derecho Humana (2012) señala que los diversos criterios para determinar la complejidad de un proceso, resalta (i) la complejidad de la prueba; (ii) la pluralidad de sujetos procesales o la cantidad de víctimas; (iii) el tiempo transcurrido desde la violación; (iv) las características del recurso consagradas en la legislación interna; y (v) el contexto en el que ocurrió la violación; reconociendo lo anotado así mismo por esta Corte (2005) que las condiciones de un país, sin importar que tan difíciles sean, generalmente no liberan a un Estado parte en la convención Americana de sus obligaciones legales establecidas en eses tratado, salvo en los casos en ella misma establecidos; atendiendo estos seria la autoridad competente, en el caso de Colombia, el aparato legislativo, en atención a los principios de seguridad jurídica, fundamentar y garantizar este presupuesto.

\section{Actividad procesal del interesado}

Referente a este presupuesto la Corte Interamericana de Derecho Humanos (2002) preciso que si la conducta procesal del propio interesado en obtener justicia ha contribuido en algún grado a prolongar indebidamente la duración del proceso, difícilmente se configura en cabeza del Estado una violación de la norma sobre plazo razonable en todo caso, teniendo en cuanta la complejidad del asunto y el desinterés del actor, entre otros factores, la duración global del proceso litigioso no revestiría la importancia necesaria para declarar la violación de los artículos que protegen el derecho al acceso a la justicia y a las garantías judiciales; asi mismo ha señalado la jurisprudencia de esta corporación el desinterés, también las acciones para dilatar el proceso y hacerlo más duradero, es un aspecto que no puede pasar por alto, a si como lo manifestó esta Corte Internacional (2013) cuando preciso en el caso de estudio, la cantidad de recursos judiciales interpuestos por las partes en el mismo.

En este sentido el tribunal constato que entre ambas partes interpusieron más de treinta recursos y coincide con el Estado en que los recursos interpuestos por las partes en el proceso civil han contribuido a complejizar el proceso e influido en su prolongación; no obstante, esta actividad por parte de las partes no siempre puede ser considerado reprochable al mismo, atendiendo, lo señalo esta Corte (2014) cuando decidió que si bien el Estado de Guatemala señalo que la intervención de la señora Franco ha obstaculizado la investigación al aportar diversa información contradictoria o inconsistente que a su juicio no ha resultado útil, considero el tribunal que dicho alegato es tachado de inadmisible para justificar una demora indebida en los procedimientos, ya que en la jurisdicción interna corresponde a los órganos competentes dirigir la investigación y encauzarla de acuerdo a las estrategias o líneas de investigación determinadas por ellos para el esclarecimiento de los hechos y, en todo caso, la investigación debe ser impulsada de oficio, sin que las víctimas o sus familiares quienes tengan la carga de asumir tal iniciativa, que le corresponde al Estado.

\section{La conducta de autoridades judiciales}

Para el desarrollo del presente presupuesto se permite indicar lo ya señalado a lo largo de jurisprudencia de la Corte Interamericana de Derecho Humanos (2007) al señalar que las acciones y/o omisiones que vulneren derechos fundamentales pueden ser cometidas por cualquier autoridad pública, sea esta del poder Ejecutivo, Legislativo o Judicial; resaltando que en el caso de las autoridades judiciales, se debe deslumbrar en sus actuaciones caracterizadas con debida diligencia y celeridad; por lo que en providencia de la Corte Interamericana de Derechos Humanos (2004) de conformidad con lo estipulado en el artículo 27 
de la convención de Viena sobre el derecho de los Tratado es un principio básico del Derecho Internacional que una parte no podrá invocar disposiciones de su derecho interno como justificación del incumpliendo de un tratado en el derecho de gentes, una norma consuetudinaria prescribe que un Estado que ha ratificado un tratado de derechos humanos debe introducir en su derecho interno modificaciones necesarias para asegurar el fiel cumplimiento de las obligaciones asumidas. Los Estados no pueden incumplir estas obligaciones convencionales alegando supuestas dificultades de orden interno. Por tales razones la regulación procesal penal del Paraguay aplicada en el proceso objeto de estudio no podía ser invocada por este Estado para incumplir la garantía de razonabilidad del plazo al juzgar a la presunta víctima de conformidad con la obligación a su cargo contemplada en el artículo 8.1 de la Convención Americana.

\section{Situación jurídica de la persona involucrada en el proceso}

El plazo en el que se desarrolla un procedimiento penal debe ser razonable, y estas conclusiones se basan en criterios de razonabilidad y proporcionalidad, y que esta situación puede afectar eventualmente a las víctimas, puesto como señalo la Corte Interamericana de Derecho Humanos (2006) la Falta de conclusión del proceso penal ha tenido repercusiones Particulares para las familiares del señor Damiao Ximenes Lopes, ya que, en la legislación del Estado, la reparación civil por los daños ocasionados como consecuencia de un hecho ilícito tipificado penalmente puede estar sujeta al establecimiento del delito en un proceso de naturaleza criminal, por lo que en la acción civil de resarcimiento tampoco se ha dictado sentencia de primera instancia. Es decir, la falta de justicia en el orden penal ha impedido que las familiares del señor Ximenes Lopes, en particular su madre, obtengan una compensación civil por los hechos del presente caso; a si las cosas, observamos como la no aplicación del plazo razonable puede acarrear repercusiones a las personas involucradas; por lo que ese mismo tribunal internacional (2008) señalo:

El Tribunal considera pertinente precisar, además, que en dicho análisis de razonabilidad se debe tomar en cuenta la afectación generada por la duración del procedimiento en la situación jurídica de la persona involucrada en el mismo, considerando, entre otros elementos, la materia objeto de controversia. Si el paso del tiempo incide de manera relevante en la situación jurídica del individuo, resultará necesario que el procedimiento corra con más diligencia a fin de que el caso se resuelva en un tiempo breve.

Por lo anterior, las afectaciones de terceros debe ser valorados como criterios al momento de examinar el plazo razonable de la actuación judicial; y esta situación del mismo, no puede ser objeto de alegato que permite buscar la falta de celeridad y de eficacia de un proceso judicial.

\section{Análisis global del procedimiento}

Cuando estudiamos el plazo razonable no basta hacer un estudio de las eventuales situaciones que puedan dar demora a la justicia que se pueda ver reflejada en las distintas etapas del proceso, frente a este punto, la Corte Europea (1991), ha empleado para la determinación de la razonabilidad de los plazos en conjunto con su trámite que se llama análisis Global del procedimiento ; referente a este punto la CDIH (2004) señalo que la razonabilidad del plazo al que se refiere ese precepto se debe apreciar en relación con la duración total del proceso, desde el primer acto procesal hasta que se dicte sentencia definitiva. La Corte se pronuncio en el sentido de que, en materia penal, el plazo comienza en la fecha de la aprehensión del individuo. Cuando no es aplicable esta medida, pero se halla en marcha un proceso penal, dicho plazo debiera contarse a partir del momento en que la autoridad judicial toma conocimiento del caso; lo anterior 
sin pasar por alto cuando esta Corte Internacional (2006) afirmo que el plazo razonable al que se refiere el artículo 8.1 de la convención se debe apreciar en relación con la duración total del procedimiento penal que se desarrolla en contra de cierto imputado, hasta que se dicta sentencia definitiva.

En materia penal este plazo comienza cuando se presenta el primer acto de procedimiento dirigido en contra de determinada persona como probable responsable de cierto delito; por lo que los términos no pueden ser llamados a ser tomados por ligereza. Ahora bien, evidenciado lo anterior, podemos señalar, que en Colombia no se evidencias estos criterios al momento de hablar de plazo razonable, puesto que la razonabilidad no se desprende de la elementos cualitativos como los reconoce la CIDH, estos elementos cualitativos se volvieron cuantitativos por iniciativa legislativa que puede ser evidenciado en nuestro legislación procesal penal.

Conociendo la razón de esta cuantificación por parte de los términos, procederemos a estudiar, y anotar la realidad procesal, concluyendo por parte de este punto resaltando el análisis global del procedimiento, haciendo énfasis que como lo dijo la CIDH que el plazo razonable debe apreciarse como la relación con la duración del proceso, desde el primer acto del probable responsable, hasta la respectiva sentencia, para dar respuesta y entender este plazo no solo con criterio cualitativos, haciendo énfasis en criterios cualitativos, se hará mención al informe de estadísticas del sistema penal acusatorio (SPOA) emitido por Corporación Excelencia en la Justicia publicado el 26 de Marzo de 2020.

\section{Términos en SPOA en Colombia}

Antes de examinar el deber ser de los términos procesales, procederemos a estudiar la realidad de la duración de los procesos en la justicia ordinaria, atendiendo lo señalado en otros trabajos de investigación, en lo que resaltaremos y usaremos como base lo concluido por la Corporación Excelencia en la Justicia (2020) , esta evidencio un informe, en el que consigna por días la duración de actuación procesales, información que no será consignada de manera íntegra, puesto los que busca el escritor es evidenciar cifras que permita hacer un análisis claro, por lo que para la clasificación se hará atendiendo los cuatro ítems que examinan, sin hacer distinción en situación de flagrancia o no, los cuales serán consignados en la siguiente tabla.

Es decir que si examinamos conjuntamente la información, podemos señalar que los términos en días para que un proceso judicial ordinario que es llevado a juicio oral tiene una duración aproximadamente de 1332, lo equivalente a un poco más de tres años y seis meses se resuelve en promedio un proceso que es llevado a juicio oral recibiendo una respectiva sentencia, ya sea condenatoria o absolutoria, ahora bien, atendiendo este dato

Podemos señalar que dicha cantidad de días, no corresponde con los señalados por la ley, puesto que considera este escritor que si observamos artículos propios como son los señalados en el artículo 97 de nuestra norma procesal penal señala, que se deduce que uno de los efectos de la formulación de la imputación es la prohibición de enajenaciones de bienes sujetos a registros por termino de seis (6) meses, término que no fue impuesto por capricho del legislador, este término se enuncia puesto que se considero cuando se estaba estudiando la ley 906 de 2004, que al tratarse de un proceso penal con tendencias acusatorios, el proceso no sería tan paquidérmico como su antecesor, y consideraron que 180 días suficientes para que la situación jurídica del procesado o imputado tuviese respuesta al enfrentar a la justicia, lo cierto, es que si hoy en día escuchamos dicha premisa, nos causara solo un poco de gracia, puesto ni con los procesos abreviados, que hoy en día, se limitan a dos (2) audiencias ante el juez de conocimiento, obtiene esa pronta respuesta de justicia. 
Al observar el aparato judicial, que no contaba con ese término para resolver situación jurídica, toda vez que por mas que nuestra justicia en la ley 906 de 2004 es de característica premiar, es decir, de negociación, esto no significa que el involucrado dentro del proceso es llamado a someterse a dicho tipo de justicia, puesto seria una violación a sus garantías dentro del proceso, por lo anterior, procedió a ajustar a realidad, atendiendo los criterios señalados en el acápite de plazo razonable, señalando la procedencia de la libertad por vencimiento de términos cuando el imputado cuente con una medida de aseguramiento, que procederemos a desarrollar con mayor profundidad a continuación.

Tabla 1. Entrada y salida de procesos llevados a juicio oral

\begin{tabular}{|c|c|}
\hline ENTREDA Y SALIDA DEL PROCESO & Días \\
\hline Tráfico, Fabricación o Porte de Estupefacientes & \multirow{2}{*}{1158} \\
\hline Sentencia Absolutoria por acusación directa & \\
\hline Tráfico, Fabricación o Porte de Estupefacientes & \multirow[b]{2}{*}{1188} \\
\hline Sentencia Condenatoria por acusación directa & \\
\hline Hurto - Ordinario & \multirow{2}{*}{1391} \\
\hline Sentencia Absolutoria por acusación directa & \\
\hline Hurto - Ordinario & \multirow{2}{*}{1370} \\
\hline Sentencia Condenatoria por acusación directa & \\
\hline Homicidio & \multirow{2}{*}{1458} \\
\hline Sentencia Absolutoria por acusación directa & \\
\hline Homicidio & \multirow{2}{*}{1432} \\
\hline Sentencia Condenatoria por acusación directa & \\
\hline Delitos Sexuales & \multirow{2}{*}{1328} \\
\hline Sentencia Absolutoria por acusación directa & \\
\hline Delitos Sexuales & \multirow{2}{*}{1331} \\
\hline Sentencia Condenatoria por acusación directa & \\
\hline
\end{tabular}

\section{Libertad por vencimiento de términos}

Sea lo primero en indicar, antes de continuar con las reflexiones objeto de estudio, podemos señalar que Corporación Excelencia en la Justicia (2020) evidencio en el informe antes mencionado que para el 2019 se presentaron y se concedieron 5089 libertades por vencimiento de términos, la cual corresponde al 10\% de las causales de libertad en ese año por parte del ente del INPEC. 
Señalado lo anterior, ante tal situación, el Estado colombiano no se podía quedar quieto, y al ser reconocido como el vencimiento de términos como un derecho, así como se señalo en el primer acápite, se procedió a examinar otras técnicas, para el aumento del mismo, que quedaron plenamente identificadas y cuantificadas en nuestra norma procesal penal, como puede observarse los numerales cuarto, quinto y sexto del artículo 317 de nuestra norma procedimental, que se encuentra tasado en días, lo anterior en concordancia con el artículo 156 que señala: Las actuaciones se cumplirán en estricto cumplimiento de las actuaciones de las normas procesales. Esta articulación antes mencionado, nos trae el estricto cumplimiento de las normas procesales, y en caso de que estos no sean acatados, su respectiva consecuencia jurídica, que exige de como presupuesto esencial la inobservancia injustificada, es decir, que estas dilaciones que no han permitido avanzar el proceso como corresponde, no puede ser atribuidas a la defensa, puesto que el derecho de ser procesado dentro de un término razonable es de este mismo.

Resulta apenas razonable señalar, que si bien, los criterios para los vencimiento de términos son llamados en días, anteriormente, vale la pena aclarar, que la fase dentro de la formulación de imputación al escrito de acusación era contabilizado por días hábiles, mientras que la presentación del escrito hasta dar inicio al juicio oral, debía ser presentado en días ininterruntibles, atendiendo los criterios para cada caso, ya señalados en nuestro norma procesal penal, frente a este punto, traeremos alusión como la Corte Suprema de Justicia (2008) en su momento señalo:

Ciertamente, el numeral $4^{\circ}$ del artículo 317 del Código de Procedimiento Penal (Ley 906 de 2004), modificado por la Ley 1142 de 2007, estableció un término que se contabiliza en forma ininterrumpida, exclusivamente para recuperar la libertad, cuando transcurridos sesenta (60) días a partir de la formulación de imputación no se hubiese presentado el escrito de acusación. (Etapa investigativa).

En cambio, la Ley 1142 de 2007 no generó la obligación de contabilizar los términos ininterrumpidamente, si para acceder a la libertad provisional se invoca el numeral $5^{\circ}$ del artículo 317 de la Ley 906 de 2004, por haber transcurrido noventa (90) días, contados a partir de la fecha de la presentación del escrito de acusación, sin que se hubiese iniciado la audiencia del juicio oral. (Fase de juzgamiento). (Pág. 25).

Sin embargo esta interpretación no fue mucho lo que duro, atendiendo que al termino de un año después, la Honorable Corte Suprema de Justicia (2009) señalo:

se advierte que si bien una tal interpretación responde a criterios lógico - formales y exegéticos en desarrollo del principio de legalidad, lo cierto es que crea una distinción odiosa entre quienes se encuentran efectivamente privados de su libertad estando en la fase anterior a la presentación del escrito acusatorio y aquellos cuyos diligenciamientos ya han superado dicho estadio procesal, pues respecto de los primeros el lapso para acceder a su libertad provisional incluye los sábados, domingos y festivos, mientras que para los segundos tales días no cuentan, porque sólo se contabilizan los hábiles, de manera que, en primer lugar, se hace más gravosa de forma irrazonable la situación de éstos, y en segundo término, se quebranta el postulado, según el cual, a idénticas circunstancias de hecho corresponden las mismas consecuencias de derecho (Pág 55 - 56).

Partiendo de ese pronunciamiento se constato que los términos son tomados de manera ininterrumpida, sin hacer un distinción en que etapa procesal se encuentre el proceso; de esta manera la contabilización es en días calendario, y dicha postura se ha mantenido hasta la actualidad, tal como puede verificarse en el fallo de la misma Corte Suprema de Justicia cuando señalo los términos consagrados en las causales de libertad previstas en el artículo 317 de la Ley 906 de 2004 se cuentan de manera ininterrumpida y continúa, es decir, en días calendario y no en días hábiles (Pág. 11), por lo anterior, se da por establecido lo anterior, continuar estudiando la temática del vencimiento de termino. 
Vale la pena anotar, hacer una anotación antes de continuar con la temática, referente a que paso con los términos con que cuenta la Fiscalía General de la Nación, para presentar escrito de acusación o en su defecto presentar preclusión una vez se hubiese realizado la respectiva audiencia formulación de imputación, lo anterior recae de reflexión, puesto en la practica encontramos situaciones en la que observamos que si bien como lo dijo la jurisprudencia este es un derecho, que sucede cuando el privado de la libertad tiene este derecho, solicita la audiencia mediante su defensor, y atendiendo criterios de congestión judicial, esta no es programada de manera inmediata, esta es programada semanas o meses después, y a la fecha de dicha audiencia, el escrito de acusación se encuentra radicado y ya asignado a un juez de conocimiento, podemos señalar que este derecho ya no puede ser exigible, puesto que las condiciones dejaron de existir; referente a este punto, considera este escritor no puede en ningún momento se puede señalar que este derecho adquirido, que no ha sido reconocido por un juez de control de garantías dentro de los términos de inmediatez atendiendo los factores de congestión judicial puede ser atribuidos al procesado.

Indicamos para dar inicio al argumento antes señalado, lo manifestado por nuestra honorable Corte Constitucional (2014) que expreso las garantías que integran el debido proceso, y entre ellas el derecho a un proceso sin dilaciones injustas y en un plazo razonable, son de estricto cumplimiento en todo tipo de actuaciones, particularmente las judiciales, pues constituyen un presupuesto para la realización de la justicia como valor superior del ordenamiento jurídico. Ello es así por cuanto la concepción del proceso como un mecanismo para la realización de la justicia, impide que algún ámbito del ordenamiento jurídico se sustraiga a su efecto vinculante pues a la conciencia jurídica de hoy le repugna la sola idea de alcanzar la justicia pervirtiendo el camino que conduce a ella (Pág. 36); lo anterior atendiendo la función en cuanto a la posibilidad de control del juez constitucional de la siguiente frente a la libertad de vencimiento de termino este dijo la Corporación Constitucional (2014) que la función del juez constitucional a la hora de examinar las leyes que consagran términos procesales se limita a controlar los excesos, es decir a rechazar aquellas normas que desbordando notoriamente los principios de razonabilidad y proporcionalidad, fijen términos exageradamente largos, que redunden en un desconocimiento del los principios de celeridad, eficacia, y seguridad jurídica, o que, por manifiestamente cortos, impidan hacer efectivos los derechos de defensa y contradicción probatoria (Págs 37-38); por lo aquel al momento de valorar un derecho ya adquirido, no puede pasar por alto este examen; el derecho a un plazo razonable para ser acusado no puede ser pasado por alto, por lo anterior, en el caso de examen, no procede a llamar a subsanar la presentación posterior del escrito de acusación, toda vez, que el derecho a un plazo razonable, que como se señalo a lo largo, es un derecho fundamental y estructural al debido proceso, no solo consagrado en nuestra constitución política, este también se refleja en los convenios internacionales ratificados por el Estado colombiano.

Una vez hecha la anterior precisión, procederemos a dar paso al parágrafo tercero del artículo 317 de nuestro código de procedimiento penal, cuando este señala: Cuando la audiencia de juicio oral no se haya podido iniciar o terminar por maniobras dilatorias del acusado o su defensor, no se contabilizarán dentro de los términos contenidos en los numerales 5 y 6 de este articulo, los días empleados en ella, así mismo el inicio final, en el que señala cuando la audiencia no se hubiere podido iniciar o terminar por causa razonable fundada en hechos externos y objetivos de fuerza mayor, ajenos al juez o a la administración de justicia, la audiencia se iniciará o reanudará cuando haya desaparecido dicha causa y a más tardar en un plazo no superior a la mitad del término establecido por el legislador en los numerales 5 y 6 del artículo 317; situaciones que de una manera permite alargar ese plazo razonable ya cuantificado por parte de nuestro legislador, que permite acarrear consecuencias jurídicas; una vez contextualizado lo anterior, procederemos a estudiar estas dos situaciones de manera distinta, en los próximos dos acápites, con la finalidad, de concluir con las respectivas reflexiones que de lugar. 


\section{La audiencia de juicio oral no se haya podido iniciar o terminar por maniobras dilatorias del acusado o su defensor}

Permítanme señalar que al estudiar este, resulta pertinente señalar que podemos entender como maniobras dilatoria, que resulta un paso indispensable, puesto permitira entender esta situación; trayendo a alusión inicialmente el artículo 139 de nuestra norma procesal penal, que señala que dentro de las deberes específicos de los jueces, Evitar las maniobras dilatorias y todos aquellos actos que sean manifiestamente inconducentes, impertinentes o superfluos, mediante el rechazo de plano de los mismos; que este puede entender más que un deber, es una obligación, puesto en atención la connotación que tiene el juez dentro del proceso, este debe velar, como símbolo de justicia, que esta no presente deficiencias dentro de su natural transcurso.

La honorable Corte Constitucional (1994) busco definir lo que entendemos como dilaciones injustificadas, en la que señalo:

En ausencia de determinación legal, el concepto indeterminado "dilaciones injustificadas", debe deducirse en cada caso concreto con base en pautas objetivas que tomen en cuenta, entre otros factores, la complejidad del asunto, el tiempo promedio que demanda su trámite, el número de partes, el tipo de interés involucrado, las dificultades probatorias, el comportamiento procesal de los intervinientes, la diligencia de las autoridades judiciales etc. Sin embargo, en ciertos casos, es el propio legislador, en guarda de valores superiores, el que determina el contenido y alcance del aludido concepto, para lo cual establece términos perentorios cuyo incumplimiento desata consecuencias que bien pueden mirarse como riesgos conscientemente asumidos por el ordenamiento para no lastimar un bien superior. En estos eventos, el derecho fundamental a un proceso público sin dilaciones injustificadas, adquiere prevalencia sobre consideraciones puramente orgánicas y funcionales propias del aparato de la justicia (Pag.38).

Así mismo, encontramos fallos de nuestra honorable Corte Suprema de Justicia multiplicidad de pronunciamiento en el que ha sido contundente al señalar que mientras las dilaciones no sea imputable al operador judicial, no se le puede sancionar a este mismo y en consecuencia no se puede dar el vencimiento de términos, es decir, debe el procesado y la defensa técnica asumir dicha consecuencia que se de cualquiera de las peticiones que por estos imprentadas, sea viables o no, prospere o no; lo anterior en concordancia con la jurisprudencia de la Corte Suprema de justicia (2002) donde manifestó que la inexorablemente cada una de dichas actuaciones implica la prolongación del trámite por períodos aisladamente considerados y perfectamente individualizados que en el contexto del proceso pueden repercutirle negativamente por dar lugar a superar los términos máximos legalmente establecidos no solo para la configuración de un motivo liberatorio sino para el adelantamiento oportuno de las etapas que componen el trámite (Pág.17), enlistado de unas actividades de la defensa, que son productos de otros pronunciamientos de la misma Corporación (2000) donde resalto:

si bien la ley permite al procesado o su defensor durante las oportunidades legalmente previstas demandar el recaudo de aquellas pruebas que reúnan los presupuestos de conducencia y pertinencia, y establece que cuando esto suceda el juzgador está en la obligación de proveer su práctica, de todos modos la escogencia de la oportunidad para hacer uso del derecho, conlleva necesariamente la carga de soportar la incidencia que ello tenga en la duración del proceso o los intereses que defiende, de manera que sea que la prueba pedida se decrete o se rechace por el órgano jurisdicente, en una y otra eventualidad la parte que a través del pedido estimula el pronunciamiento judicial, asume las consecuencias derivadas de su actuación, las que dependen no solamente del sentido en que se expida la decisión que provoca, sino de la oportunidad y términos en que eleve la solicitud. 
(...)

Es así, como ante el inminente vencimiento de términos que para la instrucción o el juicio establece la ley, el defensor o el procesado a su arbitrio pueden optar entre solicitar el recaudo de las pruebas que consideren conduzcan a establecer la verdad sobre los hechos objeto del proceso, o que incumplan los requisitos previstos para su admisibilidad; provocar con o sin razón pronunciamientos judiciales y posteriormente ejercer el derecho de controvertirlos; promover colisiones de competencias, o recusar al funcionario judicial; solicitar nulidades inexistentes; demandar la expedición de copias de lo actuado; pedir la postergación de diligencias o la ampliación de términos; pretender la libertad del reo con o sin fundamento; o propiciar cualquier otra clase de incidente de similares características, sobre todo lo cual el funcionario ha de pronunciarse afirmativa o negativamente acorde con la realidad que el proceso evidencia; pero sea que cualquiera de las peticiones presentadas prospere o se rechace, inexorablemente cada una de dichas actuaciones implica la prolongación del trámite por períodos aisladamente considerados y perfectamente individualizados que en el contexto del proceso pueden repercutirle negativamente por dar lugar a superar los términos máximos legalmente establecidos no solo para la configuración de un motivo liberatorio sino para el adelantamiento oportuno de las etapas que componen el trámite, pero mientras dicha dilación no sea imputable al funcionario judicial, el procesado y su defensor, como una sola parte en el proceso, han de asumir las consecuencias previstas en el ordenamiento cuando en el proceso se establezcan los eventos de haber prohijado actuaciones que como maniobras dilatorias, uno u otro pudieren llevar a cabo."

Lo anterior puede señalar el escritor, que si bien, en ocasiones y en la práctica, observamos muchas técnicas o estrategias jurídicas por parte de los defensor técnicos en maniobras en defensa de los derechos del involucrado dentro del proceso, sin embargo, encontramos situaciones en que este ejercicio se encuentra fundamentado en la ética profesional de los mismos, el ejercicio correcto al derecho de la defensa; cuando encontramos estas situaciones, en la que la parte, sustenta en debida forma su ejercicio, y en consecuencia se considera procedente, bajo ninguna premisa o de ningún modo puede ser catalogado como una estrategia dilatoria el velar por las garantías y derechos del procesado.

\section{Causa razonable fundada en hechos externos y objetivos de fuerza mayor, ajenos al juez o a la administración de justicia}

Ahora bien, analizando la segunda situación, debemos entender el termino causa razonable, un término, que dentro de la practica resulta fácil de entender, sin embargo, cuando estamos tratando con garantías y derechos referidos la libertad, no puede ser considerado como una tarea que debe ser tomada a la ligera, por lo anterior, para dar respuesta a este término nos referiremos a un pronunciamiento de la Honorable Corte Constitucional (2008) señalo:

El condicionamiento atiende a que la justificación de la causa razonable debe fundarse en hechos externos y objetivos constitutivos de fuerza mayor, irresistibles e insuperables, ajenos al juez o a la administración de justicia, sin constitucionalidad de la preceptiva analizada, a que en todo caso la audiencia se iniciará cuando haya desaparecido dicha causa y a más tardar en un plazo no superior a la mitad del término establecido por el legislador en el numeral $5^{\circ}$ del artículo 317 de la Ley 906 de 2004 (Pág. 53) 
De lo anterior, se desprende la situación de fuerza mayor, un tópico que no puede ser observado de manera ajena a la situación actual por la que viven la actualidad, lo anterior se desprende, de lo siguiente, si examinamos, nuestro código de procedimiento penal, hoy en dia observamos como la virtualidad a tomado una gran preponderancia dentro del sistema judicial, lo anterior señala, que si bien, entendemos que si el juez, el fiscal, la defensa y por su puesto la penitenciaria en caso que no se cuente con la voluntad por parte del agente de renunciar a la audiencia que se programa, cuenta con elementos de comunicación que permite que la audiencia pueda celebrar de manera virtual, la situación de fuerza mayor resultaría mucho más complicado de demostrar, sin embargo, para darle más fuerza a los argumentos, procederemos a señalar que se puede entender por fuerza mayor o caso fortuito, y para este traeremos los señalado por la Corte Suprema de Justicia (2018)

Al respecto, es preciso recordar que el evento de fuerza mayor o el caso fortuito se encuentra definido en el artículo $1^{\circ}$ de la ley 95 de 1980 como el imprevisto a que no es posible resistir, como un naufragio, un terremoto, el apresamiento de enemigos, los autos de autoridad ejercidos por un funcionario público, etc; es decir, ha de tratarse de fenómenos externos al sujeto cuyo comportamiento se analiza, que reúnan las características que antaño estereotipan la figura, esto es, la imprevisibilidad (hechos súbitos sorpresivos, insospechados, etc.) y la irresistibilidad (que los efectos del hecho no puede ser exitosamente enfrentados o conjurados por una persona común), lo cual no sucede cuando una persona se encuentra privada de la libertad y por eso solo hecho, tal y como ocurre en el presente caso, pues no se demostró que hubiera imposibilitado allegar de alguna forma la prueba, e inclusive otorgar poder a un abogado para que la representara y mucho menos que la interesada directa no hubiera suplido esa ausencia (Pág. 15).

Por lo anterior, en síntesis, si no se examinan características del evento como imprevisibilidad y irresistibilidad, debidamente sustentados, no podemos hablar de que las audiencias no se pudieron celebrar.

\section{Conclusiones}

Sea lo primero en reiterar que la detención preventiva, tiene, entonces, una duración precaria o temporal porque su finalidad no es sancionatoria, no está dirigida a resocializar, a prevenir el delito ni a ejemplarizar, sino que su finalidad es puramente procesal y tiende a asegurar el resultado exitoso del proceso penal, por lo anterior la persona goza siempre del principio de inocencia y a ser tratado como tal, sin importar la aceptación y casi la imposibilidad de contradicción a esa inferencia razonable a la que fue sometido en la medida de aseguramiento, este se presume inocente hasta que un juez conocimiento dentro de un estadio procesal resulta su situación jurídica; ahora bien, es claro que al ser temporal esta no puede ser llamada a ser indefinida y esta sujeta a un plazo razonable que ya se encuentra debidamente cuantificados en nuestra norma procesal y estos se contabilizan en días calendario, sin importar la etapa procesal en la que se encuentre, no se permite hacer una objeción que en atención que la rama judicial presta sus servicios de lunes a viernes, se contaran en días hábiles, lo anterior se deduce, puesto que la medida de aseguramiento y la privación de la libertad de esa persona, no es de días hábiles, es de días calendario; no puede ser tela de discusión en ningún momento si este es un beneficio, ya nuestra jurisprudencia fue clara al señalar que este es un derecho con que cuenta una persona, que no solo se encuentra reconocido en nuestra constitución de manera expresa, los convenios ratificados por Colombia también lo contiene; que si bien, estos términos pueden ser extendidos atendiendo las excepciones que consagra nuestra normatividad procesal penal, entre esas las dilaciones injustificadas adoptadas por parte de la actitud del procesado y su defensor, en realizar maniobras que permitan dilatar el proceso y alargar mas los plazos, sin embargo, es claro que ejercer la defensa técnica, atendiendo criterios profesionales y ejercer estos mismos 
que son ofrecidos por parte de nuestra normatividad, como son los recursos o las nulidades, no pueden ser tachadas de dilaciones injustificadas, puesto como su mismo nombre lo indica, es justificada, puesto están se encuentran encaminadas a garantizar derecho de la segunda instancia y así mismo, garantías al debido proceso; cuando es llamado a situación de fuerza mayor o caso fortuito, se debe evidenciar que son situaciones imprevisibilidad y irresistibilidad, estas deben ser justificadas y llamadas a la realidad, no basta con encontrar una excusa que permita ser llamada a prosperar, debe ser examinada si de verdad esta misma no permite la realización de la misma.

\section{Referencias Bibliografícas}

C. E. (2020). Sistema de Estadísticas del Sistema Penal Oral Acusatorio. Bogotá.

Colombia. Corte Constitucional, Sentencia C-300 de 1994 (M.P. Eduardo Cifuentes Muñoz 1 de Julio de 1994).

Colombia. Corte Constitucional, Sentencia C-1198 de 2008 (M.P. Nilson Pinilla Pinilla 4 de Diciembre de 2008). Colombia. Corte Constitucional, Sentencia C-390 de 2014 (M.P. Alberto Rojas Ríos 26 de Junio de 2014).

Colombia. Corte Suprema de Justicia, Sentencia No. 15327 (M.P. Fernando Arboleda Ripoll 5 de Diciembre de 2000).

Colombia. Corte Suprema de Justicia, Sentencia No. 17089 (M.P. Edgar Lambona Trujillo 16 de Diciembre de 2002).

Colombia. Corte Suprema de Justicia, Sentencia Radicado 17011 (M.P. Mario Mantilla Nougues 11 de 04 de 2010).

Colombia. Corte Suprema de Justicia, Sentencia Radicado 37678 (M.P. Maria del Rosario Gonzalez Muñoz 30 de 05 de 2012).

Colombia. Corte Suprema de Justicia, Sentencia Radicado T-85126 (M.P. Jose Luis Barcelo Camacho 20 de 04 de 2016).

Colombia. Corte Suprema de justicia, Sentencia No. 49734 (M.P. Eugenio Fernández Carlier y otros 24 de Julio de 2017).

Colombia. Corte Suprema de Justicia, Sentencia SC3731-2018 (M.P. 6 de Septiembre de 2018).

Colombia. Corte Suprema de Justicia. Sala Penal, Sentencia No. 30066 (M. P. Javier Zapata Ortiz 26 de Junio de 2008).

Colombia. Corte Suprema de Justicia. Sala Penal, Sentencia No 30363 (M.P. Maria del Rosario Gonzalez de Lemos 4 de Febrero de 2009).

Corte Europea, Corte H.R., Vernillo Judgment (20 de Febrero de 1991).

Corte Interamenricana de Derecho Humanos, Caso Ricardo Canese Vs Paraguay (31 de 08 de 2004).

Corte Interamericana de Derecho Humanos, Caso Mémoli Vs Argentina (22 de 08 de 2013).

Corte Interamericana de Derecho Humanos, Caso Genie Lacayo Vs Nicaragua (29 de 01 de 1997).

Corte Interamericana de Derecho Humanos, Caso Cantos Vs Argentina (28 de 11 de 2002).

Corte Interamericana de Derecho Humanos, Caso Garcia Asto y Ramirez Rojas Vs Perú (25 de 11 de 2005).

Corte Interamericana de Derecho Humanos, Caso Ximenes Lopez Vs Brazil (4 de Julio de 2006).

Corte Interamericana de Derecho Humanos, Caso Lopez Alvarez Vs Honduras (1 de Febrero de 2006).

Corte Interamericana de Derecho Humanos, Caso Juan Humberto Sanchez Vs Hoduras (7 de 06 de 2007).

Corte Interamericana de Derecho Humanos, Caso Valle Jaramillo y otros Vs Colombia (27 de Noviembre de 2008). 
Corte Interamericana de Derecho Humanos, Caso Furlan y familiares Vs Argentina (31 de 08 de 2012). Corte Interamericana de Derecho Humanos, Caso Favela Nova Brasília Vs Brasil (16 de 02 de 2017). Corte Interamericana de Derechos Humanos, Caso Suárez Rosero vs Ecuador (12 de 11 de 1997). Corte Interamericana de Derechos Humanos, Caso Tibi Vs Ecuador (7 de Septiembre de 2004). Corte Interamericana de Derechos Humanos, Caso Veliz Franco y otros Vs Guatemala (19 de 05 de 2014). 
